\title{
ELEMENTOS PARA EL ANÁLISIS DEL DISCURSO POLÍTICO EN EL ESCENARIO INTERNACIONAL
}

\section{ELEMENTS FOR THE ANALYSIS OF POLITICAL DISCOURSE IN THE INTERNATIONAL ARENA}

Leandro E. Sánchez

Recibido: enero de 2011

CeRPI - IRI -UNLP*

Aceptado: marzo de 2011

E.mail.: Leandrosanchez13@yahoo.com.ar

Palabras clave: discurso político, política exterior, metodología.

Keywords: political discourse, foreign policy, methodology.

Resumen: A partir de considerar que el análisis interdisciplinario y crítico de las relaciones entre las estructuras y las estrategias del discurso, la cognición social, la interacción y las relaciones de la sociedad habilita al análisis del discurso a hacer aportes serios al estudio de estructuras, conflictos y problemas sociales. El objetivo de este trabajo es abordar el discurso que el ex presidente de la Nación Argentina, Néstor Kirchner, ha efectuado en distintos escenarios internacionales para determinar, dentro de los límites del corpus seleccionado, la correlación y la congruencia del mismo dentro y fuera de la región.

Abstract: After considering the interdisciplinary and critical analysis of the relationship between structures and strategies of discourse, social cognition, interaction and relationships of the society enables the analysis of discourse to make serious contributions to the study of structures, conflicts and social problems. The aim of this paper is to address the speech the former president of Argentina, Néstor Kirchner, has performed in various international settings to determine, within the limits of the selected corpus, the correlation and congruence of the same inside and outside the region.

(*) Centro de Reflexión en Política Internacional (CeRPI) del Instituto de Relaciones Internacionales (IRI) de la Universidad Nacional de La Plata (UNLP), Argentina. 


\section{Presupuestos epistémicos}

El presente trabajo supone un espacio de convergencia de métodos cualitativos, dentro de estos el análisis lingüístico, ubicando este espacio en el marco del paradigma interpretativo.

De manera que, como se ha señalado, el análisis crítico de las relaciones entre las estructuras y las estrategias del discurso, la interacción y las relaciones de la sociedad habilita al análisis del discurso a hacer aportes serios al estudio de estructuras, conflictos y problemas sociales. La interpretación ${ }^{1}$ del corpus propuesto implica detecta la pluralidad de sentidos del mismo, esto es, entender que el discurso político, como la mayoría de los discursos, consta de un sentido directo, literal, que designa por exceso otro sentido indirecto, secundario, figurado, que no puede ser aprehendido más que a través del primero.

Desde el punto de vista de la sociología y a pesar de la existencia de diversas perspectivas teóricas (co)presentes, es posible discernir temas concurrentes en la teoría social: en primer lugar, la mayoría de las teorías insistente en el carácter activo y reflexivo de las conductas humanas y rechazan el supuesto de que los actores no pueden controlar ni comprender dichas fuerzas; en segundo término, el lenguaje se ubica en las actividades concretas de la vida cotidiana de una determinada forma y es, en parte, constitutivo de estas actividades.

Giddens $(1990,74)$ sostiene que el lenguaje puede ser estudiado por medio de tres aspectos de la producción y reproducción del lenguaje:
Bajo el aspecto de su producción en cuanto serie de actos de locución de un hablante.

Como medio de comunicación en la interacción, donde la constitución del sentido es una realización intersubjetiva de entendimiento mutuo en un intercambio continuo.

Como estructura el lenguaje no es poseído por ningún hablante en particular, y sólo puede ser conceptualizado como una característica de a comunicación entre hablantes.

Sobre la base de este conjunto de supuestos, y sin indagar en los aportes de autores de la talla de Goffman, Cicourel o Schutz entre otros, es necesario hacer referencia, por más desprovista de la profundidad analítica que requeriría, a la Teoría de la acción comunicativa de Jürgen Habermas (1999). Este autor entiende que la epistemología se ocupa de la relación entre el lenguaje y la realidad, mientras que la hermenéutica se ocupa, al mismo tiempo, de la triple relación de una emisión que sirve: como expresión de las intenciones de un hablante, como expresión del establecimiento de una relación interpersonal entre el hablante y el oyente y, como expresión sobre algo que hay en el mundo.

De acuerdo con esta orientación las funciones de la lengua serían tres:

La reproducción cultural o actualización de las tradiciones

La integración social o coordinación de diversos planes de actores en la interacción social.

La socialización o interpretación cultural de las necesidades. 
Para Habermas (1999, 153-196), sólo el concepto de acción comunicativa presupone al lenguaje como un medio de entendimiento en el que hablantes y oyentes se refieren desde el horizonte preinterpretado que su mundo de la vida presupone, simultáneamente a algo objetivo, en el mundo social y en el mundo subjetivo, para negociar definiciones de la situación que pueden ser compartidas por todos.

Por otro lado, desde el punto de vista de la semiótica o la semiología, la irrupción del concepto de discurso (al margen de su carácter polisémico) significó una ruptura con la lingüística, al tiempo que abrió la posibilidad de una reformulación conceptual.

De acuerdo a lo establecido por Eliseo Verón (1987) la teoría de los discursos sociales es un conjunto de hipótesis sobre los modos de funcionamiento de la semiosis social, entendiendo esta como la dimensión significante d los fenómenos socales en tanto procesos de producción de sentido.

Ahora bien, esta teoría de los discursos sociales descansa sobre una doble hipótesis, que obviamente marca el propósito y objetivo de este trabajo: en primer lugar, toda producción de sentido es necesariamente social (cualquier proceso significante se explica por sus condiciones sociales de producción); en segundo lugar, todo fenómeno social es un proceso de producción de sentido, cualquiera fuera el nivel de análisis.

\section{Aproximación metodológica: el Corpus discursivo}

El corpus de este trabajo esta compuesto por los discursos pronunciados por el ex presidente en tres escenarios internacionales distintos, a saber: en las Naciones Unidas (ONU), en el MERCOSUR y en el resto del mundo.

El muestreo, necesario debido a la heterogeneidad del fenómeno social estudiado y obviamente por cuestiones prácticas, es en este caso un muestreo no probabilístico sino intencional, pero que intenta ser lo más representativo posible. Es por ello que se seleccionaron documentos de tres ámbitos distintos, respetando la periodicidad habitual en el que son formulados ${ }^{2}$, y que abarcan todos los años del ex presidente al frente del ejecutivo.

A su vez, con esta selección de discursos se intentó subrayar la idea de un auditorio ajeno y heterogéneo, en mayor o menor medida, a la realidad política doméstica del país. Es por eso, que si bien es posible encontrar discursos de Kirchner formulados en el país y con propósitos o temáticas de índole internacional, se tomaron únicamente discursos pronunciados en el exterior (15 en total).

\section{Condiciones sociales de producción}

Como sabemos es el contexto -comunicativo y social- en el que el discurso se 
produce el que determina el significado y alcance de las emisiones, la producción de estas y el contenido de las interpretaciones.

Así, en un contexto de unipolaridad (condición) y primacía (estrategia) norteamericana, el debate sobre las opciones estratégicas para los países centrales y periféricos suele concebirse por medio de las dicotomías tradicionales que han dominado la literatura sobre el tema: alineamiento versus confrontación o plegamiento versus equilibrio de poder.

De manera que de acuerdo a esta concepción, los países pueden defender y promover sus intereses en cooperación o competencia con Estados Unidos, o recurriendo a alternativas intermedias. En ese contexto se ubicó nuestro país en los primeros años de gobierno de Kirchner, en un contexto de iniciativas multilaterales (G-20, CAIRNS, MERCO-SUR, etc.), tanto desde el punto de vista político (seguridad incluida) como económico (reestructuración de la deuda externa).

A su vez, el discurso del ejecutivo estuvo marcado por una fuerte confrontación desde el punto de vista discursivo con el Fondo Monetario Internacional. Incluso se podría decir que desde el inició mismo hasta el final de dicha administración pudo percibirse que la relación entre el país y el organismo internacional de crédito estuvo marcada por constantes tensiones que atravesarían distintos temas de la agenda de política exterior.

\section{Enunciación}

Siempre dentro de los factores constitutivos de todo proceso lingüístico, de todo acto de comunicación verbal propuesto por Jakobson (1986) nos detendremos dentro del acto de enunciación para el análisis.

El acto de enunciación designa el acontecimiento singular que consiste en la producción de un enunciado o una sucesión de enunciados. En un enunciado el locutor, en este caso el presidente, manifiesta una serie de valoraciones respecto de su entorno cultural y/o ideológico que hacen que su discurso este cargado de subjetividad, por el contrario sus enunciados, desde el punto de vista analítico, se desplaza entre los polos de objetividad y subjetividad.

Los enunciados conllevan marcas del hablante en su discurso, algunas permiten leer en un enunciado como el locutor selecciona, destaca u omite entidades de la situación comunicativa, llamados deícticos (Marafioti, 2002, 119120). Por otro lado, también representan marcas en las valoraciones que el locutor haga del mundo circundante los denominados subjetivemas ${ }^{3}$.

Por lo tanto el trabajo consta de dos partes, un primera parte en el que se revisaran dichas marcas, 1 ) distintos tipos de deícticos, 2) subjetivemas, 3)apelativos e 4) indicadores de modalidad; para en una segunda parte analizar los 5)componentes del discurso y su 6)interacción con el receptor (auditorio).

\section{Deícticos}

\section{Pronombres personales}

Los pronombres personales (y los posesivos) son los más evidentes y conoci- 
dos de los deícticos. En efecto, para receptar el contenido referencial preciso los pronombres personales exigen del receptor que tome en consideración la situación de comunicación de manera:

Necesaria y suficiente en el caso de yo y de tu (tu, vos, usted) que son deícticos puros.

Necesaria pero no suficiente en el caso de él, ellos, ella (s), que son a la vez deícticos y representantes.

Entre los más comunes aquí expresados encontramos: mi país, mi gobierno, mi pueblo, los cuales se observan en todos los documentos, aunque en menor medida que los pronombres plurales. Prácticamente no utiliza la primera persona.

\section{Pronombres plurales}

Aunque el nosotros no corresponde nunca, salvo en situaciones marginales, su contenido se define de la siguiente manera: el nosotros inclusivo que es puramente deíctico (yo más vos singular o plural) y el nosotros exclusivo (yo más el singular o plural).

Nuestro país, nuestra organización, nuestras regiones, nosotros, ellos, países como los nuestros, etc., son algunos de los recursos más utilizados.

...A nosotros nos urge transformar estas oportunidades en ámbitos propicios para encontrar los instrumentos que lleven a obtener los medios prácticos para la ejecución de las ideas que portamos respecto de lo que debe ser nuestro futuro. (doc. MERCOSUR 2003, párrafo 4)

...Ellos harán su mea culpa y nosotros veremos crecer la cantidad de pobres si les volvemos a hacer caso.... (doc. ONU 2004, pág. 4, párrafo 12)

\section{localizaciones temporales}

Expresar el tiempo, significa localizar un acontecimiento en el eje antes/después respecto a un momento (t) tomado como referencia. La localización temporal se realiza mediante el doble juego de las formas temporales de conjugación verbal, que explota casi exclusivamente el sistema de localización deíctica, y el de los adverbios y locuciones adverbiales.

La mayoría de los recursos utilizados, en este caso, sirven para destacar un contexto político histórico general (tras el fin de la guerra fría), para hacer referencia y tomar distancia del pasado inmediato (durante el pasado reciente, hace cinco años, durante la década de los '90) o bien, para señalar las mejoras que han tenido lugar en el presente y su potencial proyección futura (hoy, actualmente).

... Durante el pasado reciente en muchos de nuestros países vivimos períodos de alto crecimiento, con bajas tasas de generación de empleo, alta concentración del ingreso y un significativo aumento de la pobreza e indigencia. (doc. ONU 2004, pág. 2, párrafo 15)

... Hoy el mundo transita tiempos de cambio, en el marco de una globalización que crea oportunidades y riesgos sin precedentes. (doc. III Foro Europa, pág. 2, párrafo 2)

\section{Demostrativos espaciales}

Según Marafioti $(2002,119)$ este tipo de localizador espacial es estructurado de acuerdo a un sistema ternario compuesto por: 
aquí/acá: próximo al hablante.

ahí/: próximo al oyente.

allí/allá: en el campo de referencia de una tercera persona, «el no interlocutor».

En el caso de los discursos seleccionados, la localización espacial cumple la función de ubicar al locutor en un doble posicionamiento: geográficamente, como esfera de pertenencia, e ideológicamente, en el sentido de valores compartidos. Ergo, los términos más utilizados son: el sur, desde el sur y América Latina.

\section{Subjetivemas}

De acuerdo a la convención aceptada, los rasgos semánticos de los elementos léxicos que pueden considerarse subjetivos serían, entre los usados por el entonces presidente, en estos discursos:

\section{Discurso subjetivo}

En la mayor parte de los discursos seleccionados el entonces presidente asume explícitamente su opinión y/o se reconoce implícitamente como fuente evaluativo de la información. Así es posible citar numerosas intervenciones.

...Entendemos que el mal que aqueja al mundo es la profundización incesante de la brecha existente entre pobres y ricos. Una realidad mundial marcada por una pobreza y una exclusión sin precedentes nos está indicando que no habrá prosperidad posible mientras subsistan los niveles de desigualdad entre los países y al interior de los países, como los que afectan a mundo actual. (doc. China 2004, pág. 1, párrafo 5)

...Desde nuestra perspectiva, las amenazas contemporáneas ala paz proviene tanto de la acción criminal del terrorismo como de la proliferación de armas de destrucción masiva, de las violaciones masivas a los derechos humanos como de la ausencia de participación política democrática. (doc. ONU 2004, pág. 2, párrafo 3)

\section{Adjetivos evaluativos axiológicos}

Además de la referencia a la clase de objetos a los que se les atribuye la propiedad, el sujeto de la enunciación y su sistema de evaluación, aplican al objeto un juicio de valor.

Entre estos, es posible distinguir aquellos utilizados para describir la realidad social del país y e cono sur (laceramente, acuciante, sufriente), los que resaltan el carácter positivo de las medidas del gobierno (estrategia seria y consistente) y los que remarcan el carácter equívoco de las medidas adoptadas por los Organismos Internacionales de Crédito, principal contradestinatario del discurso ( $f a-$ laces políticas proteccionistas, actual rumbo perverso, visión arcaica).

\section{Adjetivos evaluativos no axiológicos}

Estos implican una evaluación cualitativa y cuantitativa del objeto, sin enunciar un juicio de valor ni un compromiso afectivo del locutor. Muy poco utilizados en el discurso del ex presidente, la mayoría son empleados para la descripción de resultados económicos (elevada tasa de crecimiento, importantes ingresos, crecimiento sustentable). 


\section{Apelativos}

En términos generales, cuando un término del léxico es empleado en el discurso para mencionar a una persona, se convierte en apelativo. Los apelativos se usan como la primera, segunda y tercer persona para designar a la persona que habla, el locutor; aquella a quien se habla, el destinatario o alocutor; y aquella de la cual se habla, el delocutor. Se los Ilama respectivamente, actos locutivos, elocutivos y delocutivos.

En el discurso presidencial los apelativos más usuales son los pronombres propios, especialmente para referirse a su para destinatario (Naciones Unidas, la comunidad internacional, Europa), aunque también utiliza adjetivos con función apelativa (mi querido, mi buen amigo) para referirse a los presidentes del bloque regional, resaltando e carácter amistoso de la relación.

.... Exhortamos al Reino Unido a dar pronto cumplimiento al llamado de la comunidad internacional a reanudar esas negociaciones. (doc. ONU 2004, pág.5, párrafo 8).

...nuestro querido amigo presidente Ricardo Lagos.... (doc. MERCOSUR 2005, pág. 5, párrafo 3).

\section{Indicadores de modalidad}

Según Hermann Parret, el problema de la modalidad, considerado desde la enunciación corresponde a una de las dos direcciones (complementarias) en que tiende a dispersarse. Mientras la deictización es ego céntrica, la modalización es ego fugal. Es decir que la organización de las modalidades esta orientada a partir de una comunidad enunciativa (Maingueneau, 1980).

Así es que la modalidad de enunciación corresponde a la relación, que en el texto, el sujeto de la enunciación establece con el interlocutor, alocutario (en términos de la argumentación) con el auditorio. Mientras que

...la modalidad de enunciado se refiere a la manera en que se presenta el contenido del enunciado en relación con al verdad o la falsedad (en ese caso de habla de modalidades lógicas) o según juicios apreciativos (modalidades apreciativas). La relación entre la modalidad y el dictum se puede ubicar en una escala de lo implícito a lo explícito (Maingueneau, 1980).

\section{Modalidad d enunciación de posibilidad}

....La posibilidad de sumar nuevos miembros como la República Bolivariana de Venezuela, además de una nuestra de vitalidad de nuestro camino de integración, puede ser un hito que marque una ampliación en el espacio del MERCOSUR a escala universal. (doc. MERCOSUR 2005, pág. 2, párrafo 2).

...de modo que ambos gobiernos podemos contribuir al bienestar de nuestros pueblos. (doc. China 2004, pág. 1, párrafo 8).

\section{Modalidad apreciativa de obligación}

...Es claro que Europa y América Latina deben coordinar la defensa de sus pos- 
turas comunes, sostenidas en los organismos internacionales, para concretar avances en estos diversos campos de acción. (doc. III Foro Europa, pág 5, párrafo 4).

\section{Modalidad apreciativa predictiva}

...De otro modo, sólo contará con capacidad para reclamar teóricas reformas estructurales sobre cuyos resultados nadie garantiza nada, para seguir luego su sucesión constante de autocríticas. (doc. ONU, 2005, pág. 4, párrafo 10).

\section{Componentes}

Este nivel, según Eliseo Verón (1987, 1988), opera como una especie de articulador entre el enunciado y la enunciación, definiendo las modalidades (antes mencionadas) a través de las cuales el anunciador construye su red de relaciones con el imaginario; de manera tal, que es posible distinguirlos siguientes componentes:

\section{Descriptivo}

Este comporta simultáneamente una lectura del pasado y una de la situación actual o presente, es por eso que su principal función es la de constatación. Predominan los verbos en presente del indicativo (saber colectivo tipo nosotros o la patria, a veces el propio líder).

El componente descriptivo cumple, de acuerdo a lo que se puede observar en el corpus, la función de destacar los acontecimientos históricos relevantes para, por medio de un conector de conclusión, abordar la influencia de dichos fenómenos en la situación actual.
...Hace ya más de 500 años que Europa y América protagonizan el encuentro de dos universos culturales, uno de los momentos más singulares de la historia de la humanidad. Las civilizaciones originarias de América recibieron el impacto monumental de la cultura Europa, este aporte cultural fue absorbido y transformado por el mestizaje de los siglos, dando lugar a un nuevo mundo. Aquel mestizaje físico, cultural y social, los combates por la independencia de nuestras repúblicas y la adopción de los ideales de libertad y dignidad de los seres humanos, contribuyeron juntos a forjar la actual personalidad de América. (doc. III Foro Europa, pág. 1, párrafo 4)

Al mismo tiempo, este componente permite destacar los avances, sobre todo de índole económica, alcanzados; expuestos de manera técnica objetiva.

...La República Argentina es esfuerza por consolidar un proyecto de crecimiento sustentable, empleo y producción, con inclusión social, justicia social y equidad. La actividad económica ha crecido a un ritmo anual del 8.7 por ciento en el 2003, y suponemos que superará el 8 por ciento en este año. [...] Esto en un marco de baja inflación, incremento de la recaudación fiscal, importante superávit, política monetaria prudente previsible, crecimiento de las reservas y mejora del mercado interno en cuanto a consumo e inversión... (doc. MERCO-SUR 2004, pág. 1, párrafo3)

\section{Didáctico}

A través de este componente, el enunciador político no evalúa una situación, sino que enuncia un principio ge- 
neral, no describe una coyuntura determinada, sino que formula una verdad universal o con pretensión de serlo. Los principios se enuncian en el plano intemporal de la verdad, de allí que su enunciación es puramente subjetiva.

...Nuestra adhesión a los valores comunes en relación a la necesidad del mantenimiento de la paz mundial, el fortalecimiento de las Naciones Unidas, el valor del multilateralismo, la solución de controversias por medios pacíficos, la no ingerencia en asuntos internos de otros Estados, resulta una muy buena base para acrecentar nuestra recíproca colaboración. (doc. China 2004, pág. 1, párrafo 4).

Este extracto sintetiza perfectamente la dimensión idealista o principista de la interpretación del deber ser de la integración internacional que el presidente hacía propio en todo sus discursos como basamento para la acción del país.

\section{Prescriptivo}

Marca explícitamente una regla deontológico, esto es, el orden del debe ser, ya sea mediante un carácter impersonal, en el cual el enunciador no busca articularse explícitamente en la legitimación de la regla en cuestión, o un imperativo universalizable.

Obviamente, dada la estrategia dis-cursiva de un discurso pronunciado en el exterior, donde el orden de la constatación, persuasión y convencimiento prevalecen, este componente en el discurso del presidente concentra el mayor número de apelaciones orientadas hacia el pre-destinatario y el paradestinatario.
...Desde la perspectiva de estas ideas que expresamos, nuestros humildes puntos de vista respecto de la situación actual, debemos encarar la revisión del MERCOSUR buscando las vías adecuada para su profundización con el incremento de papel de sus instituciones regionales, para su ampliación, comprendiendo su integración a más países que los actuales y para cambiar, fortaleciendo su papel en la política internacional. (doc. MERCOSUR, 2003, pág. 3, párrafo 2).

\section{Programático}

El componente programático es el del orden del poder hacer, es decir, se promete, se anuncia, se compromete. Se caracteriza por el predominio de las formas verbales en infinitivo y obviamente, en futuro.

En algunas ocasiones, este componente es edificado en torno a la oposición entre el enunciador y el contradestinatario (ej. organismos financieros internacionales), como una fuerte acentuación del colectivo de identificación (el bloque regional).

... la necesidad de llevar a la práctica los mecanismos necesarios que permitan la porción y puesta en ejecución de nuevas y fructíferas actividades entre nuestras regiones, lo que habrá de permitir el crecimiento y expansión de nuestras economías (doc. Cumbre América del Sur - Países Árabes 2005, pág. 1 párrafo 3). 


\section{Receptor del mensaje}

En la categoría de receptor podemos distinguir entre destinatarios directo e indirecto que pueden estar físicamente presentes o ausentes, pueden tener 0 no la responsabilidad de responder, y la respuesta puede ser inmediata o diferida.

Eliseo Verón (1987, 16-17) entiende que el discurso político se dirige en forma simultánea a otro negativo y otro positivo, así, al construir su destinatario positivo y negativo, el enunciador entra en relación con ambos. De manera que el mencionado autor distingue entre predestinatario, contradestinatario y paradestinatario.

El predestinatario s un tipo de receptor que participa de las mismas ideas, adhiere a los mismos valores y busca los mismos objetivos que el enunciador. Básicamente, se trata del ámbito regional en sus distintas denominaciones (países periféricos, la región o el MERCOSUR).

La relación entre el enunciador y el predestinatario adquiere la forma característica de lo que se ha denominado como colectivo de identificación, el cual implica pertenencia; estas son entidades enumerables, esto es, plausibles de fragmentación y cuantificación. Se expresa en el nosotros inclusivos en el plano enunciativo.

En el marco de los discursos seleccionados es posible establecer un escalograma ascendente, donde la base es siempre la Argentina, y el techo sería la comunidad internacional. Esta identificación no sólo es geográfica, sino también ideológico política.

...El MERCOSUR es nuestro bloque de pertenencia regional.... (doc. MERCOSUR 2004, pág. 3, párrafo 2).

Es evidente que el campo discursivo de lo político implica un enfrentamiento entre anunciadores. El contradestinatario es el destinatario negativo, es excluido del colectivo de identificación y es esta definición excluyente la que compone la esencia del mismo. En este caso se produce una inversión de creencia, en el sentido de que lo que resulta verdadero para el enunciador e falso para el contradestinatario y viceversa.

Dada la coyuntura y la doble necesidad de contar con el apoyo del auditorio local para propósitos de política interna y resolver la reestructuración de la deuda externa, el principal contradestinatario de su discurso durante este período fueron los organismos internacionales de crédito (organismos financieros internacionales, multilaterales y de los países centrales) como así también el Reino Unido por, la aún no resuelta, disputa por las Islas del Atlántico Sur.

...Es cierto que visiones sesgadas que abrevan en las usinas del pensamiento único intentan debilitar nuestra integración y quieren plantear las cosas falsamente, buscando imponer una interpretación de los hechos de modo contrario a la verdad. (doc. MERCOSUR 2005, pág. 2, párrafo 6).

Finalmente, Verón revela la presencia de un tercer destinatario, el paradestinatario $(1987,13)$. Se trata de un sector que se 
mantiene, en cierta forma, "fuera del juego» y que de acuerdo al análisis que dicho autor hace de la posición respecto de la creencia la hipótesis es la de la suspensión de la creencia. Al paradestinatario se dirige todo aquello que conforma el orden de la persuasión.

En este caso, el presidente entiende que la consecución de sus objetivos políticos depende de la proximidad que logre con los distintos centros de poder mundial, regional y subregional, es por eso que dependiendo del ámbito en el cual se pronuncio el discurso se selecciono el paradestinatario necesario (países centrales o periféricos).

\section{Il. Relación con el auditorio}

Teniendo en cuenta que el adiestramiento para el uso del lenguaje en función descriptiva y argumentativa es probablemente la causa del rápido desarrollo intelectual que ha permitido a los seres humanos conseguir en pocos milenios el dominio sobre otros animales, incluso sobre otros miembros de la misma especie, es que introducimos este apartado.

La situación argumentativa se da originariamente en un marco conflictivo (especialmente en el discurso político). Para Perelman (1970), el conflicto en su realidad irreductible más evidente es e malentendido. De las diferentes posiciones que se manejan en un intercambio discursivo surge la argumentación, la posibilidad de imponer a otro un punto de vista, una ideología, una forma de pensar y actuar.
Toda argumentación modifica el estado de cosas; es por eso que cada sociedad posee instituciones para debatir entre personas «virtualmente competentes» (incluso la sociedad internacional posee instituciones de este tipo) y otras que sólo se encarga de ejecutar acciones. Es claro, que no todos pueden debatir cualquier cosa donde sea. Y como sea.

En algunos casos, como todos los documentos que conforman el corpus existen reglas preestablecidas para organizar el tema exponer. El propósito de ello sería organizar un tratamiento minimamente equilibrado.

Perelman define el auditorio como el conjunto de aquellos en quienes el orador quiere influir con su argumentación. Ahora bien, el orador construye de manera más o menos conciente el auditorio al que se dirigen sus discursos, lo que implica: en primer lugar, debe existir por parte del argumentador una voluntad de coincidencia entre el discurso y su auditorio; y en segundo lugar, este, no se puede dejar ganar exclusivamente por su por su propia voluntad sin tomar en cuenta los condicionamientos del auditorio.

Es por eso que la fueraza de los argumentos es proporcional al grado de acrecentamiento que provoca. Pero como el auditorio no se maneja únicamente por criterio racionales. Perelman somete su propia definición a la norma de racionalidad social externa: un argumento tiene el valor del auditorio que lo admite (1970, 129).

Entonces, los puntos de partida sobre los cuales el orador construye su argumentación serían: por un lado, hechos, 
verdades y presunciones; y por otro lado, valores, jerarquías y lugares de preferencia. Estos permiten, desde mi punto de vista, resaltar los recursos que el entonces presidente utilizaba en sus discursos como plataforma argumentativa.

\section{Hechos y verdades}

Conforman objetos sobre los que la audiencia, en términos generales, se ha puesto de acuerdo y no es necesario incrementar la adhesión.

...Desde nuestra perspectiva, las amenazas contemporáneas ala paz proviene tanto de la acción criminal del terrorismo como de la proliferación de armas de destrucción masiva, de las violaciones masivas a los derechos humanos como de la ausencia de participación política democrática. (doc. ONU 2004, pág. 2, párrafo 3).

Lo que sucede cuando surge un conflicto con un elemento que se considera incompatible es que este pierde su estatuto y se transforma en un hecho ilusorio o en una verdad aparente.

...Pero la estabilidad y seguridad se ven también afectadas por el hambre y la pobreza extrema, por la exclusión social, la ignorancia y el analfabetismo, por la propagación de enfermedades y epidemias y por el daño irreversible al medio ambiente. (doc. ONU 2004, pág. 2, párrafo 3).

\section{Presunciones}

Son opiniones que no pueden ser probadas aunque la adhesión a ellas puede ser reforzada o suprimida sosteniendo lo opuesto. En el discurso presiden- cial es posible encontrar más de un ejemplo de este tipo, pues abundan los subjetivemas.

...Del drama de los países sobre endeudados puede concluirse que las recetas únicas, con pretensión de ser universales y aplicables bajo cualquier circunstancia, tiempo y lugar, resultan ser sólo aproximaciones ideológicas a cuestiones concretas que sólo pueden ser resueltas con realismo, flexibilidad y actitudes preactivas. (doc. ONU 2004, pág. 4, párrafo 7).

\section{Valores}

En primer lugar debemos reiterar que los valores influyen sobre los cursos de acción. Brindan razones para preferir un tipo de conducta sobre otra, una perspectiva de análisis frente a otra o una justificación, aunque no siempre son aceptados como buenas razones.

Esto es así porque la mayoría de los valores son particulares y en todo caso compartidos por un grupo específico.

Los denominados valores universales pueden ser considerados de tan diferentes maneras que su pretendida universalidad sólo puede concebirse como una aspiración de acuerdo, ya que desaparece tan pronto como se trate de aplicar dicho valor a una situación concreta. Diversos autores, distinguen en el funcionamiento argumentativo valores concretos (como pueden ser los que representarían a nuestro país o región en una determinada coyuntura histórica).

...Esta decisión política de integrarnos es consecuencia de la democratización experimentada en la región, que posibilita 
cambios en los conceptos y en las prácticas dentro de cada uno de los Estados del MERCOSUR y entre los países que lo integramos. La existencia de valores políticos comunes y desafíos económicos similares contribuye a poner fin a las disputas y rivalidades que en el pasado entorpecían las iniciativas de cooperación internacional. (doc. ONU 2005, pág. 2, párrafo 1).

Al mismo tiempo por otro lado tenemos valores abstractos, como la justicia y la verdad.

...Como Estado amante de la paz y comprometido con el multilateralismo, la Argentina tradicionalmente ha apoyado la solución de controversias mediante la negociación y el diálogo, conforme a criterios de equidad y justicia. (doc. ONU 2004, pág. 5, párrafo 11)

Cabe destacar, que es una de las más salientes características de los valores en este ámbito el de convertirse en el centro de conflicto sin por ello dejar de ser valores. Esto explica por qué el esfuerzo por reforzar la adhesión a valores determinados es siempre necesario y reiterativo en todo discurso político.

\section{Jerarquías}

A partir de los valores se organizan jerarquías que también tiene un lugar dentro de la argumentación y que es posible reconstruir. En este caso, el desarrollo d una economía sustentable sobre el diagnóstico ortodoxo de los organismos internacionales de crédito, la integración regional productiva por sobre las negociaciones bilaterales asimétricas, bien lo representan. También existen jerarquías dobles, esto es, cuando se considera una conducta según la posición de un agente y se argumenta desde el interlocutor y no desde la propia escala de valores.

Muchas veces las instituciones internacionales, los gobiernos de los más importantes países del orden mundial y el funcionamiento real del sistema mundial, actúan a contramano de lo que se declama respecto de la ayuda a la consecución de ciertos objetivos básicos de los países menos exitosos o desfavorecidos. Aunque justo es decirlo, ello excede el campo de lo paradojal para constituir a veces una doble moral o, para decirlo de manera más educada, un doble estándar. (doc. III Foro Europa, pág. 2, párrafo 8).

Es importante tener en cuenta que estas jerarquías como los valores que contienen no están congeladas en el tiempo, sino que sufren modificaciones tanto en el eje sincrónico como en el diacrónico.

\section{Lugares de preferencia}

Se trata de posiciones que sirven para justificar valores o jerarquías pero también tiene la característica de evaluar aspectos complementarios de la realidad.

En la mayoría de los casos el orador considera la opinión de la audiencia acerca de los temas que se trata, el tipo de argumento y las razones que parecen relevantes referidas al sujeto y a la audiencia. Ello hará que se considere a un argumento como sólido o débil y que este en condiciones de construir una estrategia argumentativa. 


\section{Conclusión}

Brodbeck sostenía que los términos no significan: nosotros significamos usándolos. Es por eso que el objetivo de este trabajo ha sido aportar unos pocos elementos acerca de las condiciones particulares (expuestas en el corpus) en que estos discursos han sido pronunciados y el modo en que dichas condiciones se ven reflejadas o refractadas, en términos de Emilio de Ipola, en el discurso del ex presidente Kirchner.

A su vez, traté de restaurarle espesor y valor en tanto acontecimiento, distinto de otros discursos políticos por su característica esencial (un auditorio exclusivamente internacional), y destacar aquellos aspectos que adquieren una preeminencia que sobrepasa aquello que aparece como su contenido literal.

Sin embargo, no podemos no advertir acerca del principal limitante del trabajo que he intentado desarrollar, y esto es, el hecho de que el discurso político no solo se trata de un fenómeno del lenguaje.

Recordemos que la importancia de la retórica en el la política esta dada por desplazamientos discursivos que conforman una herramienta para dominar los conflictos que hicieron en el contexto post 2001 de la clase política objeto de su crítica.

Para comprender mejor esto podemos tomar el concepto de hegemonía de Laclau, Laclau (2005) define hegemonía como la relación en la cual una particularidad se convierte en el nombre inconmensurable de una universalidad.
Dicho ejercicio de representación es posible porque en determinado momento histórico una serie de luchas se articulan en una equivalencia de demandas que tiene en común la negatividad frente a otro que la daña. Desde este punto de vista, la creación de las identidades políticas se asocia con la formación de efectos de frontera que permiten distinguir a los amigos de los enemigos.

Pero hay que distinguir un matiz en el nivel retórico del discurso, «el modelo liberal» (contradestinatario) se coloca como fuerza antagónica porque el gobierno delimitó su propia identidad a partir de sus diferencias con este y lo presenta como una amenaza para el pueblo o la nación (meta colectivos que conforman el nosotros inclusivo). Es decir, representa un límite para la identidad del gobierno aunque a la vez permite constituirla. Sin embargo, en la práctica el gobierno se relaciona con actores concretos, por lo que la relación pasa a ser agonal, esto es, no implica una ruptura total, ya que existe el reconocimiento de la legitimidad del otro y, por ende, espacios de negociación.

\section{Bibliografía}

De Ípola, Emilio. El discurso político. Lenguajes y acontecimientos. Buenos aires, Ed. Hachette, 1987.

Elias, Norbert. Teoría del símbolo. Un ensayo de antropología cultural. Barcelona, Península, 1994.

Goffman, Irving. La presentación de la persona en la vida cotidiana. Buenos Aires, Amorrortu, 2001. 
Habermas, Jürgen. Teoría de la acción comunicativa I. Racionalidad de la acción y racionalización social. Buenos Aires, Taurus, 1999.

Jakobson, Romman. Ensayos de lingüística general. Barcelona, Ed. PlanetaAgostini, 1986.

Laclau, Ernesto. La razón populista. Buenos Aires, Fondo de Cultura Económica, 2005.

Maingueneau, Dominique. Introducción a los métodos de análisis del discurso. Problemas y perspectivas. Buenos Aires, Ed. Hachette, 1980.

Marafioti, Roberto (comp.). Recorridos Semiológicos. Signos, enunciación y argumentación. Buenos Aires, Ed. Eudeba, 2002.

Perelman, Christian. Le champ de l'argumentación. Bruselas, Editions de IÚniversité de Bruxelles, 1970.

Ricoeur, Paul. El conflicto de las interpretaciones. Ensayos de hermenéutica. Buenos Aires, Fondo de Cultura Económica, 2003.

Schutz, Alfred y Luckmann, Thomas. Las estructuras del mundo de la vida. Buenos Aires, Amorrortu, 1977.

Vasilachis de Gaialdino, Irene. Métodos cualitativos I. Los problemas teóricoepistemológicos. Buenos Aires, Centro Editor de América Latina, 1992.

Verón, Eliseo. La semiosis social. Buenos Aires, Ed. Gedisa, 1987.

Verón, Eliseo. «La palabra adversativa. Observaciones sobre la enunciación política». En AAVV. El discurso político. Lenguajes y acontecimientos. Buenos Aires, Ed. Hachette, 1987.

\section{Notas}

${ }^{1}$ De acuerdo con la aproximación de Ricoeur la interpretación es el trabajo de pensamiento que consiste en descifrar el sentido oculto en el sentido aparente, desplegar los niveles de significación implicados en la significación literal.

${ }^{2}$ Los discursos presidenciales en el seno de las Naciones Unidas como en la Cumbre de Presidentes del MERCOSUR sólo se efectúan una vez por año, correspondiendo al primero el mes de septiembre y, generalmente, diciembre al segundo.

${ }^{3}$ Recursos lingüísticos que permiten diferenciar un discurso objetivo, que intenta borrar toda huella del anunciador, de un subjetivo, en el que el anunciador asume explícitamente su opinión y/o se reconoce implícitamente como fuente evaluativo de la información. 